\title{
Metacognitive Reading Strategy and Emerging Reading Comprehension in Students With Intellectual Disabilities
}

\author{
Natasha Cox-Magno \\ Walden University \\ Peter Ross \\ Walden University \\ Kathleen Dimino \\ Walden University \\ Andrea Wilson \\ Walden University
}

This article ventures to address the gap in special education practices by providing a metacognitive reading strategy to support the emerging reading comprehension skills of kindergarten students with intellectual disabilities. Historically, students with intellectual disabilities have low reading comprehension skills that can impede their overall academic success. There is a gap in practice regarding the identification and effective use of evidencebased reading comprehension instructional strategies for students with intellectual disabilities. Guided by Piaget's and Vygotsky's constructivist theories, the purpose of this study was to test the effectiveness of a metacognitive reading strategy on the emerging reading comprehension (ERC) skills of kindergarten students with intellectual disabilities. A single-participant, multiple baseline design with graphical visual analysis was used across four kindergarten students with intellectual disabilities to illustrate the influence of the reading intervention. All four kindergarten students showed increases in their ERC skills after the completion of the intervention. An effect-size statistic was calculated to measure the improvement in percentage rate of correct responses between each participant's baseline and intervention phase. The effect-size results indicated a $60 \%$ to $80 \%$ improvement rate difference. Therefore, for these kindergartners, the metacognitive reading strategy significantly increased the ERC skills of the participants. The implications for social change include providing teachers with effective metacognitive instructional strategies for ERC skills and for improving ERC skills among students with intellectual disabilities, thus allowing intellectual disability students greater opportunity to benefit from curriculum and instruction over time.

Keywords: emerging reading comprehension, intellectual disabilities, reading comprehension

\section{Introduction}

Emerging reading comprehension (ERC) is a prerequisite literacy skill learned through interactive reading engagement before formal classroom literacy instruction. Many researchers have indicated that children with intellectual disabilities who do not have adequate exposure to ERC will have difficulty with their future reading comprehension skills (Edwards, 2014; Girard, Girolametto, 
Weitzman, \& Greenberg, 2013; Kucirkova, Messer, \& Whitelock, 2012; Schryer, Sloat, \& Letourneau, 2015). Typically, the ERC skills of children without disabilities will develop by kindergarten (Schnorr, 2011). However, in students with intellectual disabilities, ERC skills can be delayed beyond the first grade (Schnorr, 2011). This study's findings may support the transformation of the way in which special educators think about teaching ERC to kindergarten students with intellectual disabilities by informing them about a potentially successful metacognitive reading strategy to support such students' future reading comprehension skills.

\section{Educational Issue Declaration}

Students with intellectual disabilities struggle with low reading comprehension skills (Bilgi \& Ozmen, 2014; Connor, Alberto, Compton, \& O' Connor, 2014; Reichenberg, 2014). This precursor skill to reading comprehension is often referred to as ERC (Edwards, 2014; Sandvik, Daal, \& Ader, 2014; Schryer et al., 2015). ERC is defined as students acquiring knowledge about comprehension through experiences with literature prior to traditional literacy instruction (McNaughton, 2014; Rohde, 2015). Sandvik et al. (2014) described ERC as consisting of two components: social interaction and direct instruction. At first, it was understood that the emergence of a child's literacy skills only occurred through social interactions (Sandvik et al., 2014). Recently, researchers discovered that direct instruction is another important element in the emergence of a child's literacy skills (Sandvik et al., 2014). In the case of ERC, direct instruction refers to organized, systematic guidance, not traditional systematic classroom instruction (Sandvik et al., 2014). Furthermore, when the culture and community of students with intellectual disabilities do not provide them with the opportunity to develop ERC skills, their reading comprehension abilities may be low (Rohde, 2015). In other words, children who are not exposed to planned, systematic ERC guidance prior to traditional classroom instruction may suffer in terms of poor future comprehension skills.

There is a gap in special education practice regarding effective metacognitive strategies to address the low ERC skills of students with intellectual disabilities (Courtade, Test, \& Cook, 2015; Spooner $\&$ Browder, 2015; Test, Bartholomew, \& Bethune, 2015). Many researchers have indicated that there are limited evidence-based metacognitive practices to address the low ERC skills of students with intellectual disabilities (Browder, Hudson, \& Wood, 2013; Hill \& Lemons, 2015; McLaughlin, Smith, \& Wilkinson, 2012; National Center on Educational Outcomes, 2014). Cook and Cook (2011) stated that the research-to-practice gap might be addressed by implementing evidence-based research to improve students' academic outcomes. Kindergarten students with intellectual disabilities' impeded ERC skills may be due to a lack of effective metacognitive reading strategies. A statement presented by the 2015 Annual Disability Statistics Compendium indicated that 411,048 students with intellectual disabilities received special education services under the Individuals with Disabilities Act (Houtenville, Brucker, \& Lauer, 2016). Students with intellectual disabilities continue to have weak ERC skills that impact their ability to read the level of text required to meet grade-level standards (The Arc, 2015; Beecher \& Childre, 2012; New York State Education Department, 2015; Reichenberg, 2014; Watson, Gable, Gear, \& Hughes, 2012). Although kindergarten students with intellectual disabilities receive special education services, there is still a need to address the gap in special education practices by investigating effective metacognitive reading instructional strategies to improve low reading ERC in this population.

Educators can assist students with intellectual disabilities by implementing an evidence-based intervention to enhance the ERC process (Hudson, Browder, \& Wakeman, 2013). One strategy that has shown some success in increasing the ERC skills of students with and without disabilities, but that has not demonstrated success with kindergarten students with intellectual disabilities, is one version of a metacognitive reading strategy. Hudson and Test (2011) discussed using shared story reading to increase ERC skills for at-risk preschoolers, kindergarten students, and students with mild intellectual disabilities. Qanwal and Karim (2014) suggested that teachers who ask students 
questions during reading can increase ERC. Beecher and Childre (2012) used a metacognitive reading strategy to increase the ERC skills of students with intellectual disabilities aged 7-10 years. Broek, Kendou, Lousberg, and Visser (2011) showed that a metacognitive reading strategy could increase the ERC skills of students ages 2-9 years. Additionally, Broek et al. stated that the metacognitive reading intervention used in their study to increase the ERC skills of students aged 29 years should be implemented to its full capacity in various ways.

\section{Research Rationale and Inquiry}

The rationale of this study was to examine the effects of a metacognitive reading strategy on the ERC skills of kindergarten students with intellectual disabilities. To inquire about the rational of the study, a research question and hypotheses were developed.

Research Question: What are the effects of the use of a metacognitive reading strategy on the ERC skills of kindergarten students with intellectual disabilities?

Null Hypothesis: The metacognitive reading strategy did not significantly affect the ERC skills of kindergarten students with intellectual disabilities.

Alternative Hypothesis: The metacognitive reading strategy significantly affected the ERC skills of kindergarten students with intellectual disabilities.

\section{Essential Terminology}

Emerging reading comprehension (ERC): Students acquiring knowledge about comprehension through experiences with literature prior to traditional literacy instruction (McNaughton, 2014; Rohde, 2015).

Metacognitive reading strategy: A planned questioning technique used to increase ERC skills (Yang, 2011).

Utility of intervention: Educators applying or replicating an evidence-based intervention with ease that has been proven to support the learning needs of their students (Horner et al., 2005).

\section{Literature Review}

Learning to comprehend text is support by the systematic cognitive learning process related to its executive functions (Connor et al., 2014; Bilgi \& Ozmen, 2014; Danielsson, Henry, Messer, \& Ronnberg, 2012; Doolittle, 2014; McLeod, 2017; Molen, Henry, \& Luit, 2014; Sharma, 2014; Trezise, Gray, Tafee, \& Sheppard, 2014; Yoder, 2014). This systematic learning process organization consists of assimilation, accommodation, and equilibration. Also, the systematic learning process encompasses student engagement. This learning process involves not only combining current knowledge with new knowledge, but also determining when and what knowledge is needed to understand the presented text. However, the systematic cognitive learning processes of students with intellectual disabilities are affected by deficits in their executive functions. Furthermore, the lack of connections for understanding presented text is associated with deficits in inhibition memory, working memory, short-term memory, and updating memory. Therefore, the students with intellectual disabilities struggle with understanding presented text through the lack of making connections and the organization of ideas within the given text.

It is beneficial to determine the reading comprehension deficits of students with intellectual disabilities by using evidence-based measures (Hill \& Lemons 2015; Lemons et al., 2013; Hosp, 
Hensley, Huddle, \& Ford, 2014; Kalkan \& Ozmen, 2013; Wingerden, Segers, van Balkom, \& Verhoeven, 2014, 2017). There are a variety of evidence-based measures that have been proven to determine reading comprehension performance of students with intellectual disabilities. In addition to evidence-based measures, the level of oral language in students with intellectual disabilities has been aligned with the reading performances of students with intellectual disabilities (Parkin, 2016; Ricketts, Jones, Happe, \& Charman, 2013). Therefore, educators using evidence-based curriculum reading measures and examining oral language levels will assist with finding out the reading comprehension performances of students with intellectual disabilities.

There are many proven methods to assist the reading comprehension skills of students with intellectual disabilities. One proven method includes using direct instructional techniques with a scaffolded metacognitive strategy approach (Schnorr, 2011). Another approach involves having a thick rich home literacy environment (Ricci, 2011). Also, shared read-alouds with adapted text have shown to support increasing emerging literacy skills for students with intellectual disabilities (Mucchetti, 2013). Moreover, the use of technology and constant time delay has been proven to support increasing the ERC skills of students with intellectual disabilities (Allison, Root, \& Wood, 2017; Browder, Root, Wood, \& Allison, 2015; Evmenova, Graff, \& Behrmann, 2015). Therefore, educators implementing these evidence-based instructional approaches supported increasing the comprehension skills of students with intellectual disabilities.

\section{Method}

The quantitative research design we used in this study was a single-participant multiple baseline design. This design was used to determine whether the metacognitive reading strategy affected the ERC skills of kindergarten students with intellectual disabilities. The multiple baseline design in this study was implemented across four kindergarten participants with intellectual disabilities.

We based the effects of a metacognitive reading strategy on the ERC skills of kindergarten students with intellectual disabilities on the rejection of the null hypothesis or acceptance of the alternative hypothesis. The null hypothesis could be rejected if the metacognitive reading strategy significantly affected the ERC skills of kindergarten students with intellectual disabilities. The null hypothesis could be accepted if the metacognitive reading strategy did not significantly affect the ERC skills of kindergarten students with intellectual disabilities.

The utility of intervention was implemented during the treatment phase. Because the limited cognitive abilities of students with intellectual disabilities interfere with their reading comprehension process, it will be necessary to modify the intervention by reading aloud, adapting text, and using pictures to provide them with reading comprehension support (Bilgi \& Ozmen, 2014; Damber, 2015; Hudson \& Browder, 2014). Therefore, the utility of intervention was implemented by (a) matching pictures to support text; (b) reading the text, questions, and choice of answers aloud to the participants; (c) presenting the questions purposefully throughout the text; (d) developing questions based on three story elements; and (e) ensuring that the text and questions were the same for all participants.

The site was a nonprofit private school in a major metropolitan area in the southeastern region of the United States. This school and related facility were established to provide enhanced services and education for students with various disabilities. The students who attended the school ranged in age from 3 to 8 years.

The sampling procedure was convenience sampling. The sample included kindergarten students with intellectual disabilities aged 4-6 years. These kindergarten students had already gone through special education eligibility testing and had received a diagnosis of intellectual disability. 
Table 1 provides demographic data for the participants. The students at the study's site were required to turn 5 years of age before the first of September to attend kindergarten. The participants were four kindergarten students classified with intellectual disabilities.

Table 1. Demographic Data

\begin{tabular}{lccc}
\hline Participant disability & Participant gender & Participant ethnicity & $\begin{array}{c}\text { Participant grade } \\
\text { level }\end{array}$ \\
\hline $\begin{array}{l}\text { Mild intellectual } \\
\text { disability }\end{array}$ & Female & Caucasian & Kindergarten \\
$\begin{array}{l}\text { Mild intellectual } \\
\text { disability }\end{array}$ & Female & Caucasian & Kindergarten \\
$\begin{array}{l}\text { Moderate intellectual } \\
\text { disability }\end{array}$ & Male & African & Kindergarten \\
$\begin{array}{l}\text { Moderate intellectual } \\
\text { disability }\end{array}$ & Male & $\begin{array}{c}\text { American/Caucasian } \\
\text { Caucasian }\end{array}$ & Kindergarten \\
\hline
\end{tabular}

\section{Collecting Information}

During Sessions 1, 2, and 3, the baseline data were collected. During Sessions 4, 5, 6, 7, and 8, the intervention data were collected. Each of the baseline sessions and intervention sessions was about $20 \mathrm{~min}$ in length. A fidelity check was implemented before each intervention session.

For the baseline phase, three stories were read to the participants from the Unique Learning System. The participants had a choice of three pictorial/word answers. After each story was entirely read, the participants were asked questions related to the passage. The numbers of correct responses the participants provided were documented on a data collection form.

The intervention was a metacognitive reading strategy. The intervention was part of an instructional strategy that educators at the site wished to implement. The stories used were from the Unique Learning System. During the intervention phase, questions were purposefully placed throughout the passages read for each story. The data indicated the number of correct responses the participants provided. Pictures directly represented the read passage. The participants were provided with three pictorial choices. The pictorial choices had words that described the pictures. The participants demonstrated the correct answer by choosing the correct picture-word choice in response to presented questions.

A fidelity check was implemented before each session. The fidelity check consisted of (a) ensuring that the story used for the particular session was present, (b) ensuring that the picture word symbols matched the story used for the particular session, (c) rehearsing reading the story with the purposefully placed questions, and (d) rehearsing presenting the choice of answers for the participants related to the story and purposefully place questions for the particular session.

We collected data using the secondary analysis approach. The data were collected under the auspices of the nonprofit private school internal program's assessment and steady advancement. One fundamental purpose of using the secondary analysis approach was that Walden University is unable to govern an intervention, which is a part of our data collection. Implementing the secondary analysis approach means that the data is the property of the nonprofit private school. Because the data were the property of the nonprofit private, we asked the director of the nonprofit private school to surrender the data to us for only research purposes. Likewise, the data gathering, intervention, program enlisting, or consent was decided by the nonprofit private school. 


\section{Research Materials and Measuring ERC Skills}

The reading materials to collect data in this study were derived from the Unique Learning System (N2Y, n.d.). N2Y, a prominent developer of special education programs and special education resources, developed the Unique Learning System. The Unique Learning System was developed to provide general education curriculum access to students with disabilities. This system supports the learning needs of students with disabilities by providing differentiated instruction and adapted materials. Furthermore, the Unique Learning System's curriculum is aligned with state standards.

A baseline and intervention frequency chart were used to document the correct reading responses for each participant. The frequency charts consisted of (a) the participants' assigned number, (b) the questions that were asked, (c) the name of the text used, and (d) whether or not the participants gave a correct response. We based our assessment of changes in participants' ERC skills on the number of correct responses when presented with purposefully placed questions throughout the selected Unique Learning Systems passages.

\section{Evaluating the Data}

We based the data analysis on changes in measured reading ERC skills between the baseline and intervention phases (O’Neill, McDonnell, Billingsley, \& Jenson, 2011; Parker, Vannest \& Brown, 2009). The graphed data illustrated the number of correct responses between the baseline phase and the intervention phase for each of the four participants by no overlapping data points and by the intervention data points exceeding the baseline data points. To further show the potency of the assessment of the metacognitive reading strategy, we used effect size statistic to evaluate the magnitude of the intervention. The improvement rate difference (IRD) formula determined the effect size by indicating the percentage of improved data points between the baseline phase and the assessment of intervention phase. The improved rates (IRs) are the data points in the intervention phase that did not overlap and exceeded the data points in the baseline phase. Therefore, if the results showed improvement between the baseline phase and the assessment of a metacognitive reading strategy phase, then the metacognitive reading strategy significantly affected the ERC skills of kindergarten students with intellectual disabilities.

\section{Results}

Figure 1 illustrates the baseline and intervention data for the first participant's number of correct responses. The results for the baseline data for Participant 1 were as follows: one out of three correct, two out of three correct, and two out of three correct. The intervention results for Participant 1 were as follows: three out of three correct, three out of three correct, three out of three correct, three out of three correct, and two out of three correct.

The IR intervention result was $80 \%$. This result was due to the intervention data exceeding the baseline data and the intervention data not overlapping with the baseline phase. The IRD results for Participant 1 indicated an $80 \%$ improvement between the baseline phase and the intervention phase. Therefore, the results prompted the rejection of the null hypothesis, and that the metacognitive reading strategy was understood to have significantly affected the ERC skill of this participant. 


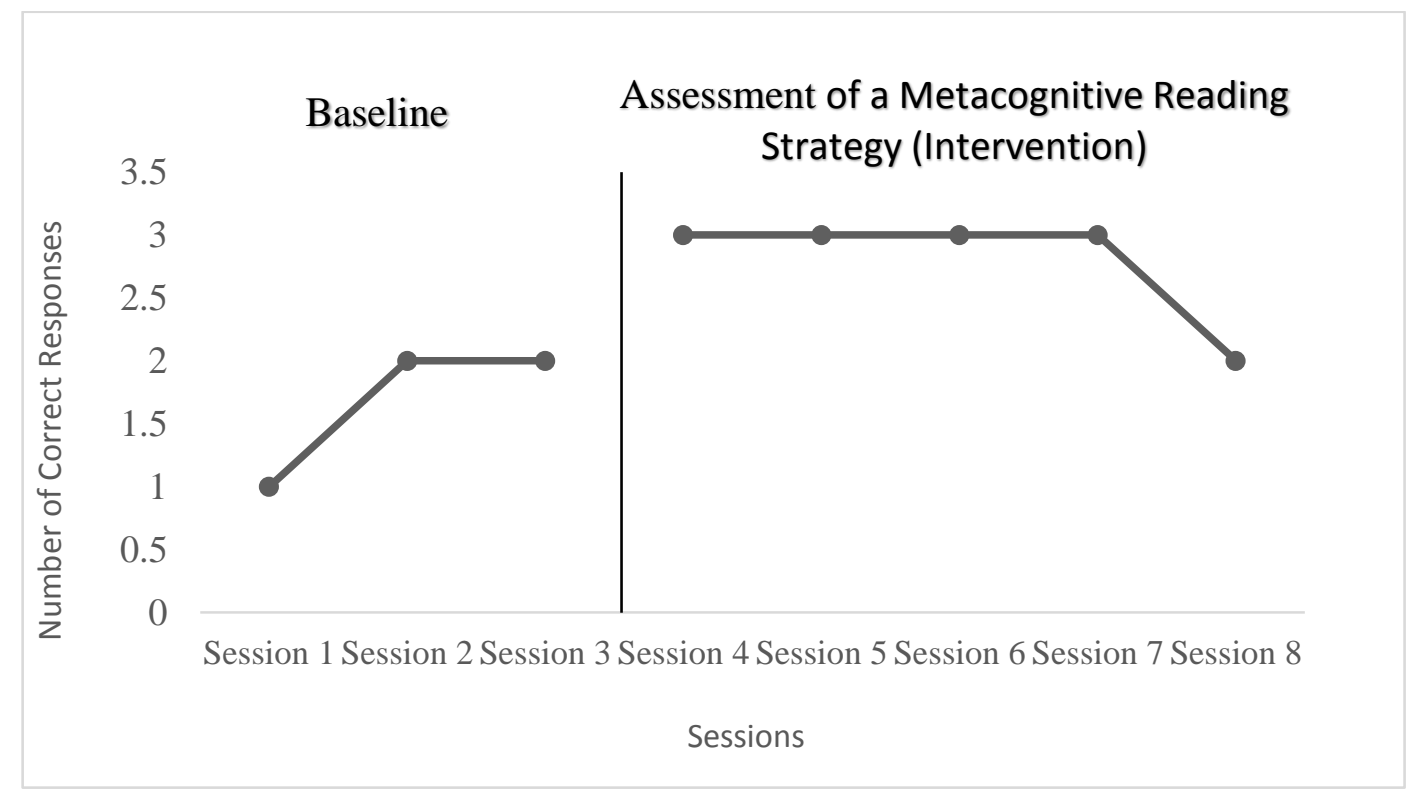

Figure 1. Participant 1 Responses Before and During Assessment of a Metacognitive Reading Strategy (Intervention)

Figure 2 illustrates the baseline and intervention data for the second participant's number of correct responses. The results for the baseline data for Participant 2 were as follows: one out of three correct, one out of three correct, and zero out of three correct. The intervention results for Participant 2 were as follows: two out of three correct, three out of three correct, two out of three correct, one out of three correct, and one out of three correct.

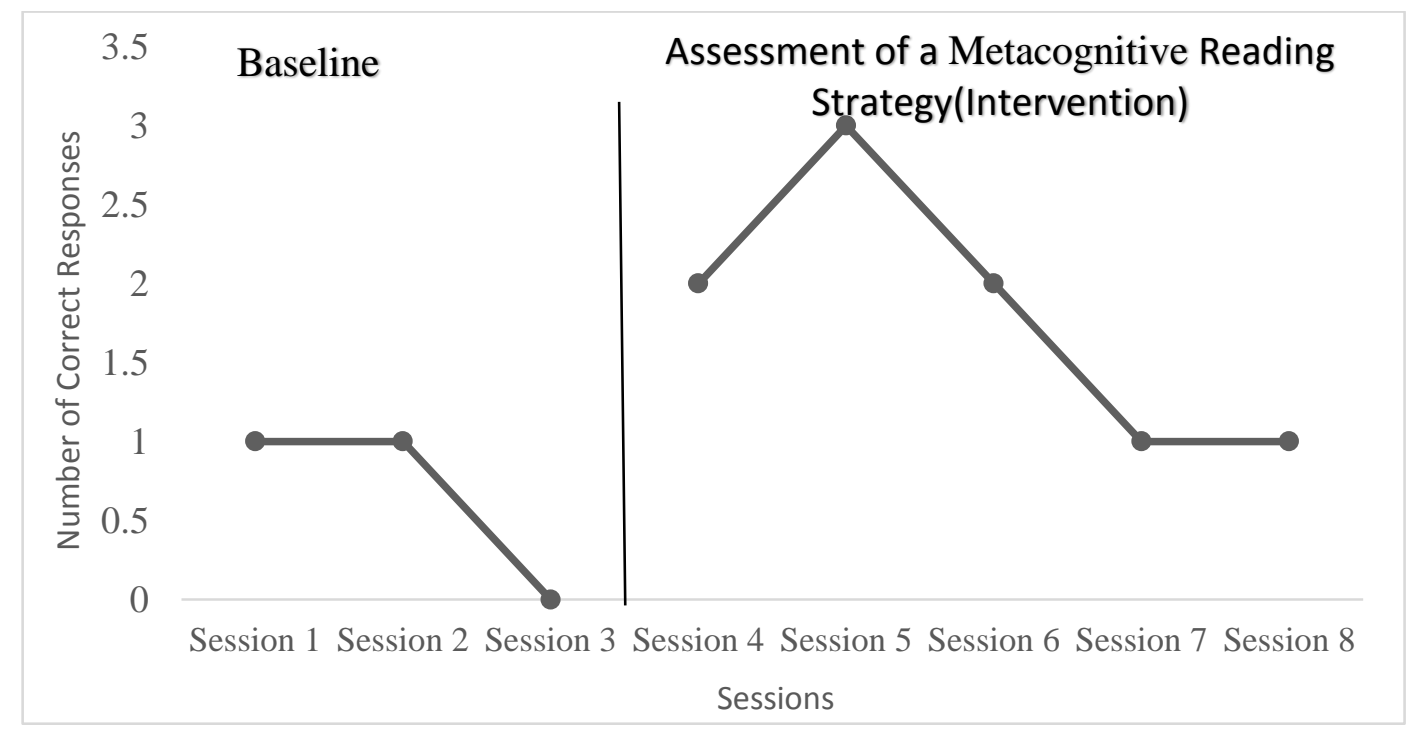

Figure 2. Participant 2 responses Before and During Assessment of a Metacognitive Reading Strategy (Intervention) 
The IR intervention result was $60 \%$. This result was due to intervention data that exceeded baseline data and intervention data that did not overlap with baseline data. The IRD intervention results revealed a $60 \%$ improvement rate between the baseline phase and the intervention phase. The results promoted the rejection of the null hypothesis and indicated that the metacognitive reading strategy significantly affected the ERC skills of this participant.

Figure 3 illustrates the baseline and intervention data for the third participant's number of correct responses. The results for the baseline for Participant 3 were as follows: one out of three correct, one out of three correct, and one out of three correct. The intervention results for Participant 3 were as follows: two out of three correct, one out of three correct, two out of three correct, two out of three correct, and two out of three correct.

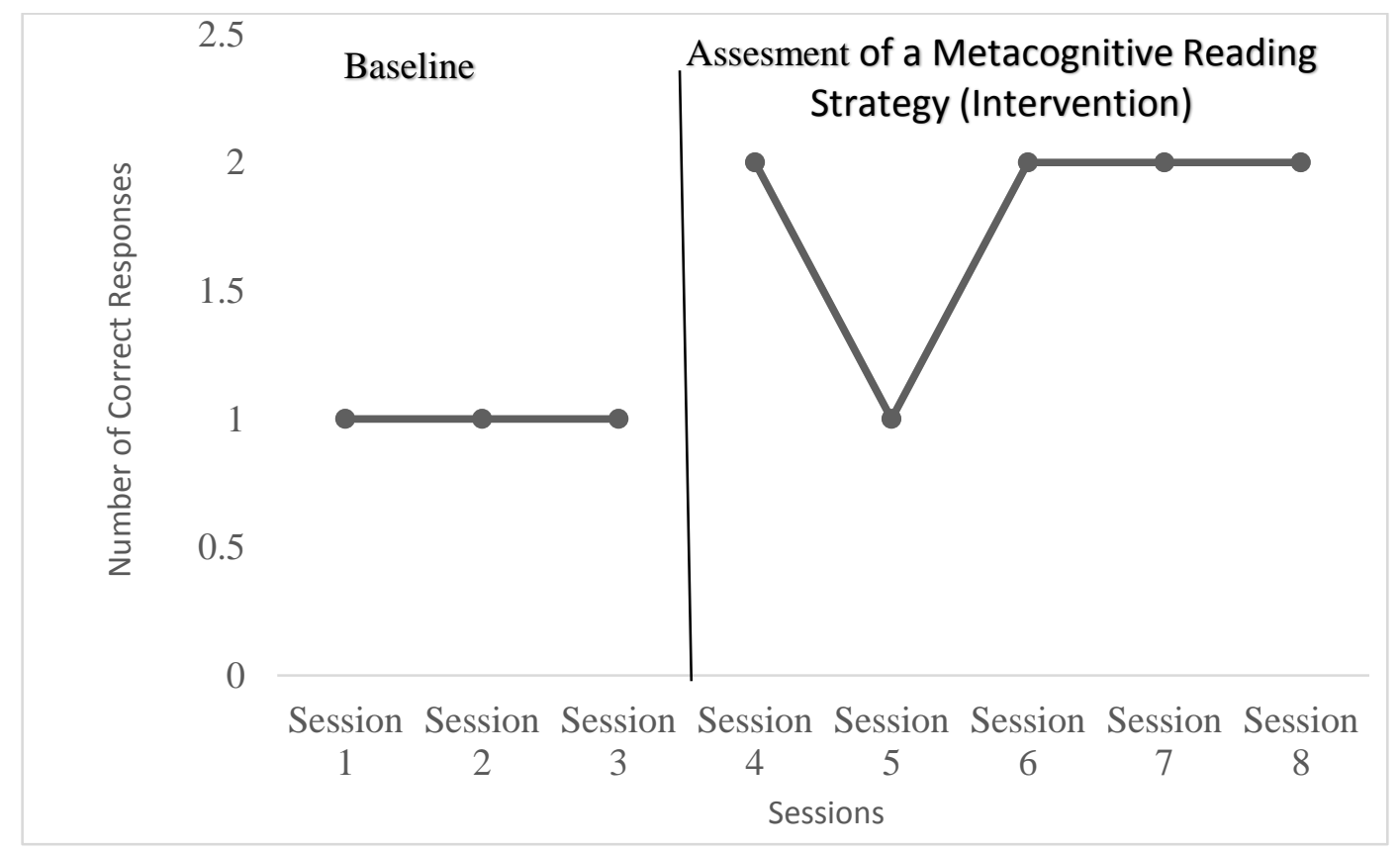

\section{Figure 3. Participant 3 Responses Before and During Assessment of a Metacognitive Reading Strategy (Intervention)}

The IR intervention result was $80 \%$. This result was due to the intervention data exceeding the baseline data and the intervention data not overlapping with the baseline data. The IRD result showed an $80 \%$ improvement rate between the baseline phase and the intervention phase. The results prompted the rejection of the null hypothesis and indicated that the metacognitive reading strategy significantly affected the ERC skills for this participant.

Figure 4 illustrates the baseline and intervention data for the fourth participant's number of correct responses. The results for the baseline data for Participant 4 were as follows: one out of three correct, two out of three correct, and zero out of three correct. The intervention results for Participant 4 were as follows: one out of three correct, three out of three correct, two out of three correct, three out of three correct, and three out of three correct. 


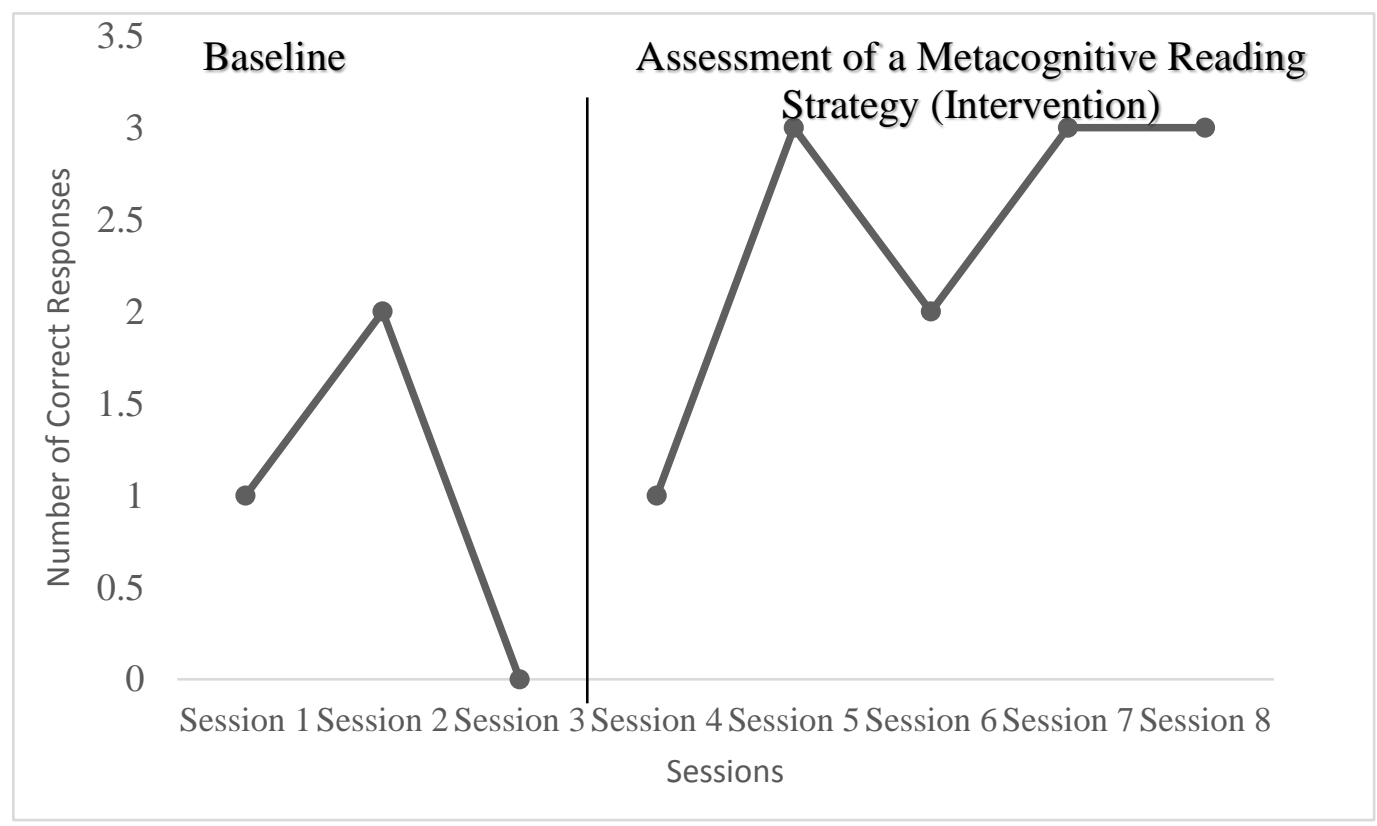

Figure 4. Participant 4 Responses Before and During Assessment of a Metacognitive Reading Strategy (Intervention)

The IR intervention data result was $60 \%$. This result was due to the intervention data exceeding the baseline data and the intervention data not overlapping with the baseline data. The IRD result showed a $60 \%$ improvement rate between the baseline phase and the intervention phase. The results prompted the rejection of the null hypothesis and indicated that the metacognitive reading strategy significantly affected the ERC skills for this participant.

\section{Discussion}

\section{Interpretation of the Findings}

In the literature, many researchers discussed using a metacognitive reading strategy that supported not only reading comprehension, but also ERC skills (Beecher \& Chidre, 2012; Qanwal \& Karim, 2014). However, the researchers in these studies did not address kindergarten-level participants with intellectual disabilities. Also, the researchers in these studies did not solely address the metacognitive strategy used in this study concerning kindergarten participants with intellectual disabilities. Therefore, we addressed the gap in special education practices by demonstrating that a proven metacognitive strategy also impacted the ERC skills of kindergarten students with intellectual disabilities.

According to Piaget's and Vygotsky's constructivism tenets, learning is developed through a cognitive building block process (assimilation, accommodation, and equilibration) consisting of gradually combining old knowledge with new knowledge to learn a new concept. The gradual cognitive building block process occurred using a direct metacognitive scaffolded instructional approach by implementing purposefully placed questions thru the presented text. Each of the questions was designed to gradually build knowledge about the topic to support the students with full-text comprehension. These constructive theories clearly supported the framework of this study. In other words, when the kindergarten students with intellectual disabilities were given specific clues about reading content, these clues appeared to create metacognitive aids that facilitated ERC skills (Bilgi 
\& Ozmen, 2014; Damber, 2015; Hudson \& Browder, 2014; Hudson et al., 2013; Shurr \& TaberDoughty, 2012; Qanwal \& Karim, 2014; Wood, Browder, \& Flynn, 2015).

\section{Caution: Research Boundaries}

There were various research boundaries presented in this study. One of the boundaries was the number of participants in the study. Although the participation pool is small, it is still within the norm for single participant designs. Another boundary was regarding the classifications of the participants. All participants were kindergarten students, and the study was limited to those kindergarten students with intellectual disabilities. Also, the external validity is more bounded with single participant designs because of the small number of participants. The subsequent replication of the ERC intervention can help increase the external validity of this intervention. In addition, the generalization of the study's findings is confided to the non-profit private schools located in large metropolitan area.

\section{Onward: Further Proposed Research}

There are several recommendations as a result of this study. One recommendation is to replicate this study to increase external validity. An additional recommendation is to determine the effects of a metacognitive reading strategy while reading on the ERC skills of kindergarten students with intellectual disabilities based on oral language levels (Parkin, 2016; Ricketts et al., 2013). This recommendation may be essential to determine whether the metacognitive reading strategy used in this study has the same impact on kindergarten students with intellectual disabilities with different levels of oral language levels. Another recommendation is to evaluate the effects of a metacognitive reading strategy on the ERC skills of kindergarten students with intellectual disabilities based on several points of time during the kindergarten school year. This suggestion will show the metacognitive reading strategy's potential cumulative effects over an academic school year concerning the ERC skills of kindergarten students with intellectual disabilities. Finally, a recommendation is to determine the effects of a metacognitive reading strategy with reading on the ERC skills of kindergarten students with intellectual disabilities across different instructional settings with different academic content (Knight, Spooner, Browder, Smith, \& Wood, 2013). In other words, it would be prudent to investigate if kindergarten students with intellectual disabilities can use the metacognitive reading strategy to comprehend expository concepts.

\section{Let's Chat}

This study was unique because it addressed an academic area that has been under researched in relation to kindergarten students with intellectual disabilities (National Center on Educational Outcomes, 2014). Also, we addressed the gap in special education ERC practices by substantiating that this metacognitive reading strategy certainly affected the ERC skills of kindergarten students with intellectual disabilities. Therefore, the results of this study added to the evidence-based literature on effective practices for kindergarten students with intellectual disabilities.

Consequently, the implementation of an evidence-based strategy can be advantageous in addressing the ERC skills of kindergarten students with intellectual disabilities (Beecher \& Chidre, 2012; Broek et al., 2011; Hudson et al., 2013; Qanwal \& Karim, 2014).

A single-participant design was used not only to determine a functional relationship, but also deemed as a research design needed to expand knowledge in special education research (Byiers, Reichle, \& Symons, 2012; Courtade et al., 2015; Horner \& Baer, 1978; Laureate Education, Inc., 2012; O'Neill et al., 2011; Rumrill, Cook, \& Wiley, 2011). The single-participant design assisted with answering the research question by identifying the effect of the metacognitive reading strategy on the ERC skills of kindergarten students with intellectual disabilities. Plus, there is a need to address 
the gap in special education practices for students with intellectual disabilities by conducting a highquality, evidence-based ERC single-participant design. Also, a multiple baseline design across participants can confirm, through systematic replication, that the intervention is responsible for the change in the dependent variable. In addition, a single-participant design is a leading methodology for investigating the impact of an intervention on students with intellectual disabilities. Therefore, the single participant design was beneficial to this study.

\section{Conclusion}

Positive suggestions for the enhancement of society (based on the results of this study) can be not only associated with increasing instructional educators' expertise but also increasing students ERC skills which, in turn, support their future reading achievement. Also, the positive suggestions for the enhancement of society based on the results of this study may address the gap in special education practices as well as add to special education literature. Furthermore, kindergarten students with intellectual disabilities will benefit by increasing their reading achievement (Edwards, 2014; Girard et al., 2013; Kucirkova et al., 2012; Schryer et al., 2015). A strong reading foundation can improve the probability of reading success in the future. Also, the results of this study can help increase the instructional expertise of teachers of kindergarten students with intellectual disabilities by implementing the ERC intervention employed in this study (Cook \& Cook, 2011). Finally, the results of this study will help address the gap in special education practices and special education literature by illustrating the positive effects of a metacognitive strategy for ERC (Courtade et al., 2015).

\section{References}

Allison, C., Root, J. R., \& Wood, L. (2017). Technology-based shared story reading for students with autism who are English language learners. Journal of Special Education Technology, 32, 111. doi:10.1177/0162643417690606

The Arc. (2015). Intellectual disability. Retrieved from http://www.thearc.org/learnabout/intellectual-disability

Beecher, L., \& Childre, A. (2012). Increasing literacy skills for students with intellectual and developmental disabilities: Effects of integrating comprehensive reading instruction with sign language. Education and Training in Autism and Developmental Disabilities, 47, 487501.

Bilgi, A. D., \& Ozmen, E. R. (2014). The impact of modified multi-component cognitive strategies in the acquisition of metacognitive strategy knowledge in the text comprehension process of students with mental retardation. Educational Sciences: Theory and Practice, 14, 707-714. doi:10.12738/estp.2014.2.1629

Broek, P. v., Kendou, P., Lousberg, S., \& Visser, G. (2011). Preparing for reading comprehension: Fostering text comprehension skills in preschool and early elementary school children. International Electronic Journal of Elementary Education, 4, 259-268.

Browder, D. M., Hudson, M. E., \& Wood, A. L. (2013). Teaching students with moderate intellectual disabilities. Exceptionality: A Special Education Journal, 21, 191-206. doi:10.1080/09362835.2013.802236

Browder, D. M., Root, J. R., Wood, L., \& Allison, C. (2015). Effects of a story mapping procedure using the iPad on the comprehension of narrative texts by students with autism spectrum disorder. Focus on Autism and Other Developmental Disabilities, 32, 1-13. doi:10.1177/1088357615611387

Byiers, B. J., Reichle, J., \& Symons, F. J. (2012). Single-subject experimental designs for evidencebased practice. American Journal of Speech-Language Pathology, 21, 397-414. 
Connor, C. M., Alberto, P. A., Compton, D. L., \& O'Connor, R. E. (2014). Improving reading outcomes for students with or at risk for reading disabilities: A synthesis of the contributions from the institute of education sciences research centers (NCSER 2014-3000). Washington, DC: National Center for Special Education Research, Institute of Education Sciences, U.S. Department of Education.

Cook, B. G., \& Cook, S. C. (2011). Unraveling evidence-based practices in special education. The Journal of Special Education, 47, 71-82. doi:10.1177/0022466911420877

Courtade, G. R., Test, D. W., \& Cook, B. G. (2015). Evidence-based practices for learners with severe intellectual disability. Research and Practice for Persons with Severe Disabilities, 36, 305318. doi:10.1177/1540796914566711

Creswell, J. W. (2012). Educational research: Planning, conducting, and evaluating quantitative and qualitative research (Laureate custom ed.). Boston, MA: Pearson Education.

Damber, U. (2015). Read-alouds in preschool: A matter of discipline? Journal of Early Childhood Literacy, 15, 256-280. doi:10.1177/1468798414522823

Danielsson, H., Henry, L., Messer, D., \& Ronnberg, J. (2012). Strengths and weaknesses in executive functioning in children with intellectual disability. Journal of Research in Developmental Disabilities, 33, 600-607.

Doolittle, P. (2014). Complex constructivism: A theoretical model of complexity and cognition. International Journal of Teaching and Learning in Higher Education, 26, 485-498.

Edwards, C. M. (2014). Maternal literacy practices and toddlers' emergent literacy skills. Journal of Early Childhood Literacy, 14, 53-79. doi:10.1177/1468798412451590

Evmenova, A. S., Graff, H. J., \& Behrmann, M. M. (2015). Providing access to academic content for high-school students with significant intellectual disability through interactive videos. Focus on Autism and other Developmental Disorders, 32, 1-3. doi:10.1177/1088357615609307

Fajardo, I., Avila, V., Ferra, A., Tavares, G., Gomez, M., \& Hernandez, A. (2014). Easy to read text for students with intellectual disabilities: Linguistic factors affecting comprehension. Journal of Applied Research in Intellectual Disabilities, 27, 212-225.

Girard, L. C., Girolametto, L., Weitzman, E., \& Greenberg, J. (2013). Educators' literacy practices in two emergent literacy contexts. Journal of Research in Childhood Education, 27, 46-60. doi:10.1080/02568543.2012.739591

Hill, D. R., \& Lemons, C. J. (2015). Early grade curriculum-based reading measures for students with intellectual disabilities. Journal of Intellectual Disabilities, 19, 311-325. doi:10.1177/1744629515574812

Hosp, J. L., Hensley, K., Huddle, S. M., \& Ford, J. W. (2014). Using curriculum-based measures with postsecondary students with intellectual and developmental disabilities. Remedial and Special Education, 35, 247-257. doi:10.1177/0741932514530572

Horner, R., \& Baer, D. M. (1978). Multiple-probe techniques: A variation of the multiple baselines. Journal of Applied Behavior Analysis, 11, 189-196.

Horner, R. H., Carr, E. G., Halle, J., McGee, G., Odom, S., \& Wolery, M. (2005). The use of single subject research to identify evidence-based practice in special education. Exceptional Children, 71, 165-179.

Hudson, M. E., \& Browder, D. M. (2014). Improving listening comprehension for students with moderate intellectual disability during literacy class. Research and Practice for Persons with Severe Disabilities, 39, 11-29. doi:10.1177/1540796914534634 
Hudson, M. E., Browder, D., \& Wakeman, S. (2013). Helping students with moderate and severe intellectual disability access grade-level text. Teaching Exceptional Children, 45, 14-23.

Hudson, M. E., \& Test, D. W. (2011). Evaluating the evidence-based of shared story reading to promote literacy for students with extensive support needs. Research and Practice for Persons with Severe Disabilities, 36, 34-45.

Houtenville, A. J., Brucker, D. L., \& Lauer, E. A. (2016). Annual Compendium of Disability. University of New Hampshire. Durham, NH: Institute on Disability. Retrieved from http://www.disabilitycompendium.org/docs/default-source/2015compendium/compendium_2015_final.pdf

Kalkan, S., \& Ozmen, E. R. (2013). A comparison of reading comprehension, reading rate and reading error performances of the students with mental retardation attending inclusive education and special education classes (The sample of Çorum Province). International Online Journal of Educational Sciences, 5, 147-187.

Knight, V. F., Spooner, F., Browder, D. M., Smith, B. R., \& Wood, C. L. (2013). Using systematic and graphic organizers to teach science concepts to students with autism spectrum disorder and intellectual disability. Focus on Autism and Other Developmental Disabilities, 28, 115-126. doi:10.1177/1088357612475301

Kucirkova, N., Messer, D., \& Whitelock, D. (2012). Parents reading with their toddlers: The role of personalization in book engagement. Journal of Early Childhood Literacy, 13, 445-470. doi:10.1177/1468798412438068

Laureate Education, Inc. (Executive Producer). (2012). $A-B-A-B$ single-subject design. Baltimore, MD: Author.

Lemons, C. J., Zigmond, N., Kloo, A. M., Hill, D. R., Mrachko, A. A., Paterra, M. F., . . Davis, S. M. (2013). Performance of students with significant cognitive disabilities on early-grade curriculum-based measures of word and passage reading fluency. Exceptional Children, 79, $408-426$.

McLaughlin, M. J., Smith A. F., \& Wilkinson T.G, (2012). Challenges for leaders in the not-so-new era of standards. In J. B. Crockett, B. S. Billingsley, \& M. L. Boscardin (Eds.), Handbook of leadership and administration for special education (pp. 281-269). New York, NY: Taylor \& Francis.

McLeod, S. (2017). Jean Piaget. Retrieved from https://www.simplypsychology.org/piaget.htm

McNaughton, S. (2014). Classroom instruction: The influences of Marie Clay. The Reading Teacher, 68, 88-92. doi:10.1002/trtr.1286

Molen, M. V., Henry, L., \& Luit, J. V. (2014). Working memory development in children with mild to borderline intellectual disabilities. Journal of Intellectual Disability Research, 58, 637-650. doi:10.1111/jir.12061

Mucchetti, C. A. (2013). Adapted shared reading at school for minimally verbal students with autism. Autism, 17, 358-372. doi:10.1177/1362361312470495

N2Y. (n.d.). Unique Learning System: Activate the potential in every student. Retrieved from https://www.n2y.com/unique-learning-system/

National Center on Educational Outcomes. (2014). Reading and students with mental retardation. Retrieved from http://www.cehd.umn.edu/NCEO/OnlinePubs/PARA/mentalretardation/index.htm 
New York State Education Department. (2015). Common Core learning standards: C\&I. Retrieved from

http://www.p12.nysed.gov/ciai/common_core_standards/pdfdocs/p12_common_core_learning_ standards_ela.pdf

O’Neill, R. E., McDonnell, J. J., Billingsley, F. F., \& Jenson, W. R. (2011). Single-case research designs in educational and community settings. Upper Saddle River, NJ: Pearson Education.

Parkin, J. R. (2016). Wechler Individual Achievement Test-Third Edition oral language and reading measure effects on reading comprehension in a referred sample. Journal of Psychoeducational Assessment, 1, 1-16.

Parker, R. I., Vannest, K. J., \& Brown, L. (2009). The improvement rate difference for single case designs. Council for Exceptional Children, 75, 135-150.

Qanwal, S., \& Karim, S. (2014). Identifying correlations between reading strategies instruction and L2 text comprehension. Journal of Language Teaching and Research, 5, 1019-1032. doi:10.4304/jltr.5.5.1019-1032

Reichenberg, M. (2014). The importance of structure text talks for students' reading comprehension. Journal of Special Education and Rehabilitation, 15, 77-94. doi:10.2478/JSER-2014-0012

Ricketts, J., Jones, C. R., Happe, F., \& Charman, T. (2013). Reading comprehension in autism spectrum disorders: The role of oral language and social functions. Journal of Autism and Developmental Disorders, 43, 807-816. doi:10.1007/s10803-012-1619-4

Ricci, L. (2011). Home literacy environments, interest in reading and emergent literacy skills of children with Down syndrome versus typical children. Journal of Intellectual Disability Research, 55, 596-609. doi:10.1111/j.1365-2788.2011.01415.x

Rohde, L. (2015). The comprehensive emergent literacy model: Early literacy in context. Sage Open, 5, 1-11. doi:10.1177/2158244015577664

Rumrill, P. D., Cook, B. G., \& Wiley, A. L. (2011). Research in special education: Data, Designs, methods, and applications. Springfield, IL: Charles C. Thomas.

Sandvik, J. M., Daal, V. H., \& Ader, H. J. (2014). Emergent literacy: Preschool teacher's beliefs and practices. Journal of Early Childhood Literacy, 14, 28-52. doi:10.1177/1468798413478026

Schnorr, R. (2011). Intensive reading instruction for learners with developmental disabilities. The Reading Teacher, 65, 35-45. doi:10.1598/RT.65.1.5

Schryer, E., Sloat, E., \& Letourneau, N. (2015). Effects of an animated book reading intervention on emergent literacy skill development an early pilot study. Journal of Early Intervention, 37, 155-171. doi:10.1177/1053815115598842

Sharma, R. K. (2014). Constructivism an approach to enhance participatory teaching learning. Gyanodaya, 7, 12-17. doi:10.5958/2229-4422.2014,00003.6

Shurr, J., \& Taber-Doughty, T. (2012). Increasing comprehension for middle school students with moderate intellectual disabilities on age appropriate text. Education and Training in Autism and Developmental Disabilities, 47, 359-372.

Spooner, F., \& Browder, D. M. (2015). Raising the bar: Significant advances and future needs for promoting learning for students with severe disabilities. Remedial and Special Education, 36, 28-32. doi:10.1177/0741932514555022

Test, D. W., Bartholomew, A., \& Bethune, L. (2015). What high school administrators need to know about secondary transition evidence-based practices and predictors for students with disabilities. NASSP Bulletin, 99, 254-273. doi:10.1177/0192636515602329 
Trezise, K. L., Gray, K. M., Tafee, J., \& Sheppard, D. M. (2014). Working memory in adolescent males with Down syndrome and males with autism and intellectual disability: Implications for classroom. Journal of Intellectual and Developmental Disability, 39, 24-34.

Watson, S. M., Gable, R. A., Gear, S. B., \& Hughes, K. C. (2012). Evidence-based strategies for improving the reading comprehension of secondary students: Implications for students with learning disabilities. Learning Disability Research and Practice, 27, 79-89.

Wingerden, E., Segers, E., van Balkom, H., \& Verhoeven, L. (2014). Cognitive and linguistic predictors of reading comprehension in children with intellectual disabilities. Research in Developmental Disabilities, 35, 3139-3147.

Wingerden, E., Segers, E., van Balkom, H., \& Verhoeven, L. (2017). Foundations of reading comprehension in children with intellectual disabilities. Research in Developmental Disabilities, 60, 211-222.

Wood, L., Browder, D. M., \& Flynn, L. (2015). Teaching students with intellectual disability to use a self-questioning strategy to comprehend social studies text for an inclusive setting. Research and Practice for Persons with Severe Disabilities, 40, 275-293. doi:10.1177/1540796915592155

Yang, K. L. (2011). Structures of cognitive and metacognitive reading strategy used for reading comprehension of geometry proofs. Educational Studies in Mathematics, 80, 307-326. doi:10.1007/s10649-011-9350-1

Yoder, S. (2014). Constructivism theory and use from the 21st century. Journal of Applied Learning Theory Technology, 4, 12-20.

The Journal of Educational Research and Practice provides a forum for studies and dialogue that allows readers to better develop social change in the field of education and learning. Journal content may focus on educational issues of all ages and in all settings. It also presents peer-reviewed commentaries, book reviews, interviews of prominent individuals, and additional content. The objectives: We publish research and related content that examines current relevant educational issues and processes aimed at presenting readers with knowledge and showing how that knowledge can be used to impact social change in educational or learning environments. Additional content provides an opportunity for scholarly and professional dialogue regarding that content's usefulness in expanding the body of scholarly knowledge and increasing readers' effectiveness as educators. The journal also focuses on facilitating the activities of both researcher-practitioners and practitioner-researchers, providing optimal opportunities for interdisciplinary and collaborative thought through blogging and other communications.

Walden University Publishing: http://www.publishing.waldenu.edu 